\title{
NARRACIONES AUTOBIOGRÁFICAS Y \\ VISUALIDADES: ENTRE LA ACADEMIA, LA \\ TECNOLOGÍA Y LA PATERNIDAD
}

FERNANDO MIRANDA

Universidad de la Republica - Montevideo, Uruguay

RESUMEN Este texto tiene como propósito reflexionar sobre las visualidades construidas en el uso de las tecnologías y medios contemporáneos a partir de pequeños episodios de la biografía personal. Quiero compartir breves anécdotas de mi vida como profesor - pero también como padre -, para pensar y reflexionar acerca de cómo armamos nuestras maneras de relaciones cotidianas y nuestras identidades de pertenencias múltiples. Las narrativas biográficas deben concebirse como objetos que pueden ser abordados desde la mirada de la investigación, es decir, en su posibilidad de observar y analizar los movimientos vitales - en este caso propios - y sacar de ellos nuevos aprendizajes y conocimientos. La inclusión que realizo acerca del lugar de las tecnologías no ignora a las grandes corporaciones que están detrás de la estructura de la comunicación digital ni de Internet. Por el contrario, considero posible producir micro-espacios de oportunidad y alternativa -aún dentro de esos dominios- para crear lugares y prácticas de cercanía, para incluir la perspectiva de un uso sensible en tanto tienen un carácter de acción humana. Este texto pretende mostrar, además, que los trazos biográficos de las personas no se producen en solitario, necesariamente involucran a otros y dan cuenta, por eso, de acontecimientos colectivos e individuales que se entremezclan.

Palabras clave: Visualidades. Biografias. Tecnologías digitales.

\section{TECHNOLOGY}

This text aims to reflect on the visualities constructed in the use of the technologies and contemporary media from small episodes of the personal biography. I want to share brief anecdotes of my life as a professor - but also as a father - to think about and reflect on how 
we build our everyday relationships and our identities of multiple affiliations. Biographical narratives must be conceived as objects that can be approached from the perspective of research, that is, in their capacity to observe and analyze the vital movements - in this case mine - and to extract from them new learning and knowledge. The inclusion I make about the place of technology doesn't ignores the big corporations that are behind the structure of digital communication or the Internet. On the contrary, I consider it possible to produce micro-spaces of opportunity and alternative - even within those domains - to create places and practices of proximity, to include the perspective of a sensitive use, as they have a character of human action. This text also intends to show that the biographic traces of people do not occur isolated, necessarily involve others and therefore represents collective and individual events that are intermingled.

Keywords: Visualities. Biographies. Digital technologies.

\section{RESUMO NARRATIVAS AUTOBIOGRÁFICAS E VISUALIDADE:}

\section{ENTRE A ACADEMIA, A TECNOLOGIA E A PATERNIDADE}

Este texto tem como propósito refletir sobre as visualidades construídas no uso das tecnologias e meios contemporâneos, a partir de pequenos episódios da biografia pessoal. Quero partilhar breves histórias da minha vida, como um professor, mas também como pai, para pensar e refletir sobre como articulamos nossas formas de relações quotidianas e nossas identidades de pertencimentos múltiplos. As narrativas biográficas devem ser concebidas como objetos que podem ser abordados de uma perspectiva investigativa, ou seja, em sua possibilidade de observar e analisar os movimentos vitais, neste caso, próprios, e extrair deles novas aprendizagens e conhecimentos. A inclusão que realizo acerca do lugar das tecnologias não ignora as grandes corporações que estão por trás da estrutura da comunicação digital nem da Internet. Pelo contrário, considero que é possível produzir microespaços de oportunidade e alternativa, mesmo dentro desses domínios, para criar lugares e práticas de aproximação, para incluir a perspectiva de uma utilização sensivel, visto que ambos têm um caráter de ação humana. Este texto pretende, também, mostrar que os traços biográficos das pessoas não são produzidos isoladamente, mas envolvem outros indivíduos e, por isso, dão conta de acontecimentos coletivos e individuais que se entre mesclam.

Palavras-chave: Visualidades. Biografias. Tecnologias digitais. 
Narrar no es sólo un arte, es además un mérito, y en Oriente hasta un oficio. Acaba en sabiduría, como a menudo e inversamente la sabiduría nos llega bajo la forma del cuento. El narrador es, por tanto, alguien que sabe dar consejos, y para hacerlo hay que saber relatarlos.

(BENJAMIN, 2005, p. 42)

\section{Circunstancias y motivos de este texto}

Nuestra formación como profesores y profesoras no solamente acontece en las etapas institucionales de la graduación, el posgrado o la prácticas profesionales.

Más bien es importante considerar aquello que ocurre a lo largo de nuestra vida, pensando que nuestra propia producción y actuación como formadores incluye visualidades cotidianas que hemos acumulado referencialmente, $y$ que están relacionadas con las imágenes que conocemos, creamos, consumimos, y distribuimos a través de distintos medios materiales o virtuales.

Para mi generación, aquellos que hemos transcurrido la infancia en los años ' 70 , han sido tradicionales, y fundamentales, la televisión en blanco y negro por supuesto -, el cine, y el cómic. En épocas de la dictadura cívico-militar en Uruguay (1973-1984), en que viví mi infancia y adolescencia, las transmisiones de televisión comenzaban a las seis de la tarde básicamente con dos posibilidades: dibujos animados norteamericanos, básicamente de los estudios de Hanna-Barbera o telenovelas argentinas.

Creo que nunca se ha dado suficiente relevancia ni profundidad de estudio y análisis a la incidencia axiológica, afectiva y sensible que estos medios y programas han tenido, en nuestras cotidianidades, para construir nociones compartidas de ser y actuar en el mundo a todo nivel.

Pero también es necesario ver que, más allá de la matriz visual que aquellas formas pudieran representar, las que también constituyen verdaderas referencias conceptuales, es de orden reconocer cómo, en las últimas décadas y ya en nuestro ejercicio docente y profesional, ha ido ejerciendo influencia, interés y necesidad la multiplicación de pantallas a nuestro alrededor.

Este texto tiene que ver, justamente, con la reflexión sobre visualidades construidas en el uso de las tecnologías y medios contemporáneos a partir de pequeños episodios de mi propia biografía. Quiero compartir breves anécdotas de mi vida como profesor -pero también como padre-, para pensar y reflexionar acerca de cómo se organizan los valores que asumimos en las identidades que construimos, y de cómo armamos nuestras maneras de relaciones cotidianas, y los modelos familiares que edificamos mientras vamos siendo profesores.

También, comparto con Ricard Huerta la preocupación acerca de cuánto estamos (auto) excluidos en general, como varones y como profesores universitarios, de reflexionar en torno a nuestras paternidades. Creo que Huerta llama acertadamente la atención sobre el punto cuando afirma que deberíamos

\section{[...] aprender a hablar de nuestra paternidad del mismo modo que hablamos de otras cuestio- nes, fundamentales o anecdóticas, sin aceptar que ser padre es ejercer como tal, dando por sentado que dicho ejercicio sucede de manera espontánea. Ser padre es complicado y por ello conviene hablar del tema. (2013, p. 12)}

Esta omisión, atendiendo a su complejidad, es la que pretendo además saldar -aunque sea en parte- con este texto, relacionando el asunto con mi condición de profesor.

Las identidades de las personas, a mi juicio, son múltiples y de carácter eminentemente cultural, en la medida en que cada entorno, el contexto social, las pertenencias colectivas, forjan distintos espacios a ocupar y diferentes roles a asumir. 
El error sería considerar que tales lugares y actuaciones tienen un carácter único y fijo.

Por el contrario, si bien estos espacios se actúan - y así se logra su reproducción matricial -, también se discuten, cuestionan y modifican en la manera en que cada uno de nosotros desplegamos nuestras acciones.

De esta forma, veremos transformada la aparente homogeneidad en los roles que el entorno cultural tiene definidos nominalmente - y los desempeños correspondientes que le son asignados -, si hurgamos más allá de la superficie, en nuestras propias (auto)biografías.

Hay así múltiples maneras de ser profesor, madre, hijo, hermana, etc. y aunque el entorno social tenga un nombre previsto para cada uno de estos lugares, llegar a la profundidad en que cada uno y cada una asume el desempeño de la denominación asignada es algo que va más allá de la superficie homogénea.

Cuando pensamos nuestras trayectorias como profesores tenemos la tendencia a observar la linealidad de nuestras vidas. Intentamos recuperar ordenadamente cuáles han sido los episodios de nuestra infancia que pueden haber influido en nuestra relación con las instituciones educativas y con la universidad; qué personajes o maestras han tenido que ver con nuestras decisiones como docentes; y como qué tipo de profesor o profesora creemos que somos; qué decisiones hemos tomado que creemos nos han permitido llegar hasta aquí y en qué circunstancias.

En definitiva, cómo han ocurrido, más o menos ordenadamente, acontecimientos significativos que han estructurado nuestra biografía académica y nos han colocado en el lugar en que estamos.

Esa tendencia a concebir las biografias como un todo, como una unidad lineal y aparentemente poco sobresaltada, ha sido suficientemente descripta y abordada por autores como Pierre Bourdieu, que han reflexionado acerca de la construcción de narrativas biográficas que tienden, a nuestro juicio, a concebirse como objetos que pueden ser abordados desde la mirada de la investigación.

En el sentido de lo afirmado por Bourdieu:

El relato, sea biográfico o autobiográfico, como el del testimonio que se confía a un investigador, propone acontecimientos que, sin desarrollarse todos y siempre en estricta sucesión cronológica (cualquiera que ha recogido historias de vida sabe que los testimonios pierden constantemente el hilo de la sucesión estrictamente cronológica), tienden o pretenden organizarse en secuencias ordenadas según relaciones inteligibles." (1989, p. 28)

Del mismo modo, trabajar con las biografías y con las historias de vida, permite conectar la experiencia individual con los contextos sociales y colectivos en los que cada profesora, estudiante o colaborador inscribe su relato, no para dar determinación a esa narración, sino también para comprender esos propios entornos.

Coincido con Fernando Hernández en que la "cuestión clave, lo que constituye la característica principal de la perspectiva metodológica de las historias de vida es su finalidad, que no es otra que conectar las narrativas personales y biográficas de profesores e investigadores con su contexto sociocultural, histórico e institucional." (2011, p. 20)

En el mismo sentido, lo que pretendemos realizar en este texto, es conectar pequeñas narrativas textuales a situaciones de contexto más amplias, que nos permitan comprender las condiciones de nuestras concepciones y actuaciones, así como las maneras en que resolvemos los múltiples requerimientos de nuestras identidades superpuestas. Como sostiene Molly Andrews ${ }^{1}$ :

1 Todas las traducciones de textos cuyos originales cuentan en idioma portugués e inglés fueron realizadas por el autor. 
Si creemos, como yo lo hago, que las historias son vitales para quiénes somos y para cómo estamos en el mundo, que estas historias cambian con el tiempo y que son únicas y culturalmente inscriptas, entonces se deduce que estas historias tienen un gran potencial para la construcción de puentes, haciendo conexiones vitales entre los individuos y el mundo de las ideas. (2012, p. 34)

En cuanto a esto, recogemos las expresiones de Souza respecto de la necesaria articulación entre la producción de las subjetividades y sus entornos contextuales que dan referencias de comprensión e interpretación. Es así que

(al invocar) a la memoria, sabemos que ella es algo que no se fija sólo en el campo subjetivo, ya que toda vivencia, aunque singular y auto-referente, se sitúa también en un contexto histórico y cultural. La memoria es una experiencia histórica indisociable de las experiencias peculiares de cada individuo y de cada cultura. (2007, p. 63)

No desconozco, sin embargo, que este relato en particular tiene un cierto contenido de dificultad. Se trata de narrar situaciones propias y personales, donde el texto se mueve en la tensión del sesgo autocomplaciente y el suficiente valor comunicable de las experiencias narradas.

Entiendo que cuando relatamos episodios de nuestra propia biografía tenemos que ponderar con equilibrio cierto nivel de objetividad, que oscila entre la rigurosidad de la mirada sobre los hechos narrados y la valoración subjetiva de la que el relato no puede desprenderse.

Es claro, así, que cuando narramos experiencias o acontecimientos biográficos hay elementos que son necesariamente objetivos -datos, fechas, hechos puntuales-, sin perjuicio de lo cual, el énfasis que damos a cada momento, las significaciones que les atribuimos, o el orden en que presentamos las situacio- nes son necesariamente subjetivos y hacen a nuestra actuación vital.

De acuerdo con Denzin (2014) los textos biográficos no pueden ser considerados como si fuesen "ventanas dentro del 'mundo real' de sujetos 'reales' que interactúan". (p. 12)

Por mi parte, considero que las personas construyen sus biografias de manera performática e interpretando esa actuación con las posibilidades y fragmentos con que cuentan como recuerdos, referencias, objetos, y visualidades; casi a la manera en que lo hacía el protagonista del film brasileño $O$ vendedor de passados (2015) en la (re)construcción de los "pasados" de sus clientes.

Pero si me embarco finalmente en esta tarea es porque creo que, más allá de cierto valor personal que este relato representa, su interés puede alcanzar a lectores diversos para pensar en sus propias formas de construcción de identidades profesionales y parentales, puestas en relación entre sí.

Quizás, como en pocos otros casos, sea demostrarme a mí mismo que puede ser válido el hecho de que “...debemos comunicar a aquellos en quienes estamos confiados que lo que traen a la mesa es de valor, y mostrarles cómo lo que saben puede ser utilizado como base para la exploración intelectual." (ANDREWS, 2012, p. 33)

Por eso entiendo que ésta es una aportación que tiene unas responsabilidades variadas porque debemos responder siempre a un conjunto de preguntas que la propia Andrews sintetiza con claridad:

¿Quién cuenta sus historias? ¿Quién permanece en silencio? ¿A quién le cuentan sus historias? ¿Quiénes son los personajes principales de las historias? ¿Quiénes están ausentes, pero estaban presentes? ¿Quién dirige el movimiento de la historia? ¿Quién tiene poder y cómo se negocia? [...] ¿Cómo se interpreta la historia? ¿Por el orador? ¿Por los oyentes? (2012, p. 34) 


\section{Pequeños relatos de historias personales}

En diciembre de 2013, colegas de la Facultad de Artes Visuales de la Universidad Federal de Goiás me hablaron de la posibilidad de realizar una estancia de posdoctorado allí.

Aceptar esta invitación me implicaría vivir en Goiânia, cuando menos, por seis meses; a más de dos mil kilómetros de distancia de mi ciudad, Montevideo, y de mi país, Uruguay.

Hasta aquí nada diferente a lo que seguramente ocurre algunas veces a muchos de nosotros, profesores universitarios, en tanto desarrollamos nuestras vidas académicas y estrechamos nuestros vínculos y redes de investigación a las que pertenecemos.

La diferencia que luego esto tiene, y para cada uno, es cuánto marca nuestras vidas o más bien, cuánto nuestras decisiones académicas y profesionales afectan nuestras relaciones y la vida de otras personas a lo largo del tiempo.

Como señala Bourdieu:

Tenemos, sin duda, el derecho de suponer que el relato autobiográfico se inspira siempre, al menos por una parte, en el deseo de dar sentido, dar razón, extraer una lógica a la vez retrospectiva y prospectiva, una consistencia y una constancia, estableciendo relaciones inteligibles, como las del efecto a la causa eficiente o final, entre los estados sucesivos, constituidos de este modo en etapas de un desarrollo necesario. $(1989$, p. 28)

De manera que el relato tiene sentido desde esta mirada, es decir, en la posibilidad de observar y analizar nuestros propios movimientos vitales y sacar de ellos nuevos aprendizajes y conocimientos.

Instalarse en cualquier ciudad extraña a la propia produce movimientos en las personas, que los adultos, supuestamente, sabemos manejar y solucionar; pero en nuestro caso familiar, debíamos decidir cómo lo resolveríamos, puesto que teníamos una niña pequeña, Maite, haciendo sus primeros pasos en la escuela.

Había que pensar que trasladarse con Maite a un país en que se habla otra lengua, en el momento en que la niña está adquiriendo sus conocimientos básicos de lecto-escritura en su idioma materno -español- y sin sus amigos y amigas más próximos, eran consecuencias también de las decisiones académicas de su padre como profesor de la universidad.

Quedarse en Montevideo era distanciarse de papá por un tiempo y modificar la rutina cotidiana de Maite, aunque estuviera en casa con su mamá.

Finalmente, concreté la invitación para Goiânia en los primeros seis meses de 2015, de la forma en que con Paola, mi esposa, consideramos que era lo mejor para nuestros trabajos y compromisos profesionales, pero especialmente para Maite. Yo me iría solo, me instalaría en la nueva ciudad, y regresaría de visita a Montevideo un par de veces durante el semestre, además de que ellas pudieran, en alguna ocasión, visitarme en Brasil.

La inclusión de este relato personal en un texto de estas características, me ha hecho pensar en la imposibilidad evidente de presuponer decisiones y soluciones a nuestras situaciones cotidianas, en la necesidad de atender las coordenadas concretas de los hechos que se nos presentan y de los caminos que debemos elegir. Como señala Souza:

Pensar en sí, hablar de sí, y escribir sobre sí, emergen en un contexto intelectual de valorización de la subjetividad y de las experiencias privadas. En este sentido, el concepto de 'sí mismo' es, como todo concepto, una propuesta organizadora de determinado principio de racionalidad. (2007, p. 68)

En este sentido, entiendo que la producción del relato es una manera de construir conocimiento al tiempo que una posibilidad meta-cognitiva respecto a reconocer y siste- 
matizar las formas en que se construyen las biografias. En otro sentido,

[...] no se trata de encontrar en los escritos de sí una 'verdad' preexistente al acto de realizar una biografía, sino estudiar cómo los individuos dan forma a sus experiencias y sentido a lo que antes no lo tenía, como construyen conciencia histórica de sí y de sus aprendizajes en los territorios que habitan, y están habitados por ellos, mediante procesos de construir la biografización." (PASEGGI; SOUZA; VICENTINI, 2011, p. 371)

En el caso que estoy narrando, el desafio personal era muy interesante para mí. Significaba profundizar en mis tareas de investigación en estudios de Cultura Visual, de educación de las artes visuales; así como ampliar los alcances de mi trabajo docente, estar cotidianamente con colegas -con los que compartimos intereses académicos y espacios de amistad personal pero que habitualmente están físicamente distantes-, y conocer nuevos estudiantes e intereses de investigación.

Por otro lado, la experiencia de vivir en el extranjero, cosa que ya había realizado durante mis estudios de doctorado, también me seducía personalmente. En algún punto era modificar la mirada del turista, o del visitante ocasional de una ciudad que conocía, por la del vecino de un barrio que se instala en la vivencia cotidiana de esa ciudad, la recorre, la reconoce...

La Facultad de Artes Visuales de la UFG, en Goiânia, era un lugar que ya conocía desde su anterior edificio y cada año, en visitas académicas breves, había visto crecer la obra del predio actual en qué trabajaría. Alli desarrollé durante unas dieciocho semanas, entre otras tareas, una asignatura para el programa de posgrado que denominé "Acontecimientos visuales y mediaciones pedagógicas en el espacio urbano". Era un tema que me interesaba, sentía seguridad en las posibilidades de desa- rrollarlo con solvencia, y consideraba suficientemente atractivo para generar interés en los estudiantes de posgrado para quienes yo era un profesor convidado del extranjero.

Por supuesto que tenía una temática en la que venía trabajando y unas referencias bibliográficas básicas, pero me propuse que, clase a clase, tendría la flexibilidad de modificarlo en función de los avances que lograra con el grupo de estudiantes.

Con alguna parte de la bibliografia del curso tuve la precaución de conseguir sus respectivas versiones en portugués, había otra serie de textos en inglés, y finalmente dejé expresamente parte de los materiales en español. Me parecía interesante -y de justicia- que quienes cursaran la asignatura debieran hacer además un movimiento hacia el profesor visitante, también en el sentido del esfuerzo del idioma.

Al comienzo del curso tuve finalmente un grupo de siete estudiantes inscriptas, con la particularidad de que todas eran mujeres: Cassia, Adriane, Carol, Mirna, Tamiris, Patrizia y Bárbara.

Personalmente entiendo que hicimos, como grupo, un muy interesante trabajo. La mejor evaluación que pude haber recibido creo que es, justamente, la que no se dice en palabras; todas las estudiantes completaron la asignatura, aprobaron el curso, y llegamos juntos, todas y yo, hasta el final del semestre.

Si en las primeras semanas teníamos necesidad de repetirnos algunas veces ciertas palabras, o buscar traducción específica de algún término, la vivencia cotidiana con las estudiantes, y en la ciudad, fue seguramente perfeccionando mi portuñol, esa mezcla de portugués y español que nos hace comprender y ser comprendidos cabalmente a quienes tenemos cierta cercanía idiomática con el Brasil.

Como soy de los que cree que la riqueza de la lengua no está en el diccionario sino en su habla cotidiana fui adquiriendo con in- 
terés ciertas "dicas" del habla cotidiana que nadie enseñaría en un curso académico de portugués. Además me divertía alguna confusión idiomática que se producía o rastrear el origen posible de algunas expresiones habituales.

Por eso entiendo, además, que tiene razón Norman Denzin cuando señala que los "textos autoetnográficos son siempre escritos (y actuados) con un 'otro' en mente. [...] El ojo de los otros dirige el ojo del escritor." (2014, p. 7). Este texto me permite también ser dirigido por los ojos de esas otras, las estudiantes que compartieron curso de posgrado conmigo y a las que me gustaría contar como lectoras de este trabajo.

De cada una aprendí cosas diferentes sobre sus propios trayectos, intereses y deseos, pero también sobre sus circunstancias, identidades y contextos, siempre variados y ricos en un país como Brasil. Por eso, es necesario “aprender cómo conectar (auto) biografías y experiencias vividas, las epifanías de las vidas, a los grupos ya las relaciones sociales que rodean y forman a personas." (DENZIN, 2014, p. 6)

Este trabajo pretende también ser un movimiento en ese sentido. Porque en tanto "aprendemos a hacer esto, debemos recordar que nuestra obligación principal es siempre con las personas que estudiamos, no con nuestro proyecto o con la gran disciplina." (DENZIN, 2014, p. 6)

\section{Los lugares de Maite}

Mientras tanto Maite, que para esa época tenía siete años, extrañaba más de lo que Paola y yo podíamos haber imaginado, y la ausencia de su padre la angustiaba. La percepción del tiempo y de la distancia para una niña de esa edad era naturalmente diversa que la de nosotros, sus padres, y esto era conmovedor para Paola y para mí.
Ahora, un tiempo después, estoy seguro que la angustia de Maite nos movilizaba por nuestras propias biografias personales y eso disminuía, probablemente, nuestra capacidad de contención hacia la niña, aunque nos esforzábamos por hacerlo bien. Paola y yo, por diferentes motivos y en distintas circunstancias, tenemos nuestras historias propias de lejanía y extrañamiento paterno, y la situación de nuestra hija removía sentimientos que conocíamos vívidamente de algún modo personal. Teníamos que sobreponernos a nosotros mismos y ayudar a Maite a sentir proximidad y tranquilidad, más allá de nuestros propios sentimientos de pérdida o "trauma" en el sentido en que autores como Norman Denzin (2014) o Andrew Herrmann (2005) lo desarrollan.

Las biografías incluyen también estas ideas y estos acontecimientos. No se puede evitar las referencias necesarias a historias de dolor o pérdida que es preciso relatar, no con un objetivo terapéutico, en este caso, sino como manera de comprender e interpretar las decisiones y actuaciones vitales de las personas y la construcción de sus identidades y roles. Entonces,

[...] el recuerdo remite al sujeto a observarse en una dimensión genealógica, como un proceso de recuperación del yo, y, la memoria narrativa, como giro significante, marca una mirada sobre sí en diferentes tiempos y espacios, lo que se articulan como los recuerdos y las posibilidades de narrar experiencias. (SOUZA, 2007, p. 63)

Volviendo a nuestra historia, durante el día el asunto siempre parecía más sencillo, Maite y yo nos habíamos puesto de acuerdo en un juego que haríamos por mail. La fórmula era muy fácil y ella lo comprendía sin dificultad, su solución es algo presente en muchos libros dedicados a niños y niñas, y consistía en sustituir palabras por dibujos alternados en la redacción. 
Figura 1 - Captura de pantalla del e-mail enviado por Maite el 2/6/2015 - archivo personal

mandame mas cosas que me gusta mucho este juego.

Ví a la Camila no camina pero Victoria si, camina re bien

Las botas son con cordones y color beige casi rosado $\mathrm{A}$. No comimos nada

Pelusa no 6

te amo sos el mejor del

sos loco

$\cdots$

Maite rápidamente captó la idea del juego y le entusiasmaba encontrar entre los dibujos disponibles en el correo electrónico aquellos que completaban sus mensajes (Figura 1).

Incluso en ocasiones era obvio que primero se interesaba por algunos de esos dibujos y luego construía la frase a partir de éstos. De manera que casi diariamente iban y venían mensajes de correo electrónico que nos permitían una conexión lúdica, cuyas sutilezas eran interesantes y curiosas. $Y$ yo comencé a guardar aquellos mensajes que eran, además, visualidades compartidas.

Debo admitir, con sinceridad, que tenía personalmente algunos prejuicios respecto a nuestras posibles conexiones en la red como manera de superar nuestro mutuo extrañamiento. Como señala Zygmunt Bauman (2005), los "espasmos de la proximidad virtual terminan, idealmente, sin dejar sobras ni sedimentos duraderos. La proximidad virtual puede ser interrumpida, literal y metafóricamente a la vez, con sólo apretar un botón."(p. 90)

Entonces es verdad que al principio no terminaba de tener confianza en esta forma de comunicación, estaba más próximo a creer, con el propio Bauman (2005), que estábamos constituyendo nuestro propio juego de relaciones líquidas, intentando sublimar, por la tecnología, una cercanía imposible.

Si "bien todos nosotros somos únicos, al mismo tiempo podemos extraer de los detalles concretos cuestiones más amplias de la cultura y de la estructura social" (Andrews, 2012, p.
35) y siempre, aún en las acciones de mayor resistencia, no podemos obviar las condiciones que esa estructura social posee.

Por tanto, tenía cierto temor que las formas de relación personal que estábamos llevando, mediadas por la tecnología, terminaran por establecer un camino sin retorno, en el sentido en que adquirieran un valor intercambiable con lo que podríamos definir como la presencia verdadera.

$\mathrm{O}$, al mismo tiempo, que constituyeran un "descompromiso", en el sentido en que lo dice Bauman:

A diferencia de las 'relaciones', el 'parentesco',
la 'pareja' e ideas semejantes que resaltan el
compromiso mutuo y excluyen o soslayan a su
opuesto, el descompromiso, la 'red' representa
una matriz que conecta y desconecta a la vez: la
redes sólo son imaginables si ambas activida-
des no están habilitadas al mismo tiempo. En
una red, conectarse y desconectarse son elec-
ciones igualmente legítimas, gozan del mismo
estatus y de igual importancia. iNo tiene sen-
tido preguntarse cuál de las dos actividades
complementarias constituye 'la esencia' de una
red! (2005, p. 12)

El caso es que por las noches la niña extrañaba más a su padre, y durante las primeras semanas de mi ausencia lloraba con angustia evidente antes de ir a dormir. Faltaba, de alguna manera, el ritual de cada noche cuando papá le contaba un cuento... y esto lo hacía más ausente.

El cuento era, en esa época, siempre el mismo. Una de las tantas variantes de relato don- 
de hay un lobo feroz, y donde los personajes son, cada noche, una oveja y sus siete corderitos. En resumen, la oveja enseña a sus corderos a no abrir la puerta a nadie en su ausencia, por la posibilidad de que fuera el lobo. Pide además a sus hijos que, si alguien va a casa y toca a la puerta, miren por debajo de ésta para descubrir, por las patas del visitante, si se trata del lobo feroz.

Cada día durante semanas, Maite había ido a dormir escuchando el mismo cuento y sin llegar nunca al desenlace, lo que probablemente hiciera que no se aburriera. Esa era la fórmula para conciliar el sueño pero, ¿cómo hacer esto a más de dos mil kilómetros de distancia? ¿Qué enseñan los estudios de Cultura Visual para resolver estos problemas? Probablemente nada... o mucho. Porque debíamos encontrar soluciones que utilizaran el juego, las imágenes visuales, y las tecnologías, para producir cercanías vitales aún en la distancia. Y eso fue lo que nos propusimos, con Maite, hacer juntos.

Hay una producción de complicidad en los vínculos afectivos a través de las tecnologías que se hace necesaria para sostener la mediación distante en base a un uso consciente del instrumento. Esto crea la posibilidad efectiva de producir nuevas reglas de juego y nos transforma en protagonistas del acontecimiento sensible. Como sostiene Mirzoeff:

\begin{abstract}
Hay un nuevo 'nosotros' en Internet, y en el uso de Internet, que es diferente de cualquier 'nosotros' que la cultura de impresión o cultura de los medios de comunicación ha visto antes. [...] Lo que todos los momentos de la cultura visual tienen en común es que la 'imagen' da una forma de visibilidad al tiempo y por lo tanto al cambio. (2016, p. 21)
\end{abstract}

Con Maite creamos, entonces, un nosotros propio, uno que pudimos realizar a partir de transformar el uso de la tecnología digital, sin someternos necesariamente a sus prescripciones ni determinismos. La usamos para nues- tros propios propósitos, y eso es lo interesante más allá de cuánto usen las corporaciones nuestros datos.

Porque esto no quiere decir ignorar por mi parte a las grandes corporaciones que están detrás de la estructura de la comunicación digital ni de Internet; lo que significa es que, siendo consciente de ello, es posible producir micro-espacios de oportunidad y alternativa aún dentro de esos dominios.

Me gusta la línea de pensamiento que constituye Ben Agger cuando dice que "Internet y estas micro-tecnologías del poder y de la práctica no pueden volver a ser puestos en una botella; Están aquí para quedarse. [...] las tecnologías de las redes sociales ofrecen un nuevo tipo de comunidad, que requiere de nuevas maneras acerca de las familias y de los yo virtuales (virtual selves)." (2013, pp. 14-15) Pero, como señala Luis Camnitzer, "un uso más modesto del poder es menos controlable y por lo tanto puede ser una forma utópica más eficiente y total" (2008. p. 35). De manera que pensar las formas de subvertir la intención colonizadora primaria de las corporaciones, aún en pequeños gestos cotidianos, contribuye a hacer la vida más humana y mejor.

Si bien las dinámicas de la red 2.0 y su incesante tráfico de visualidades constituye un “modelo de negocio en el que la producción afectiva y las interacciones vitales se convierten en la base esencial de la nueva producción económica [...] también hemos de reconocer las inmensas posibilidades emancipatorias que, en todas direcciones, se han abierto en esa tremenda intensificación de las interacciones comunicativas y afectivas a través de las redes." (PRADA, 2012, p. 37)

Así es que por la época en que mi estancia en Goiânia ocurría, hicimos con Maite un segundo acuerdo lúdico: ella se acostaría y, en las noches que no consiguiera conciliar el sueño, nos conectaríamos por Skype. De esta ma- 
nera yo la vería acostada, y ella podría ver a su padre contándole el mismo cuento de cada noche cuando estamos juntos.

$Y$ así lo hicimos, y así funcionó. Ya en la primera noche en que pusimos en práctica el asunto Maite quedó dormida escuchando el mismo cuento, como cada noche ocurría en
Montevideo, pero con nuestra alternativa acordada a más de dos mil kilómetros de distancia (Figura 2). También así es que me he quedado pensando en que al próximo tonto que diga, con tono autosuficiente, que sin tanta tecnología se vivía mejor... no va a valer la pena explicarle nada.

Figura 2 - Captura de pantalla de Skype 3/2015 - archivo personal

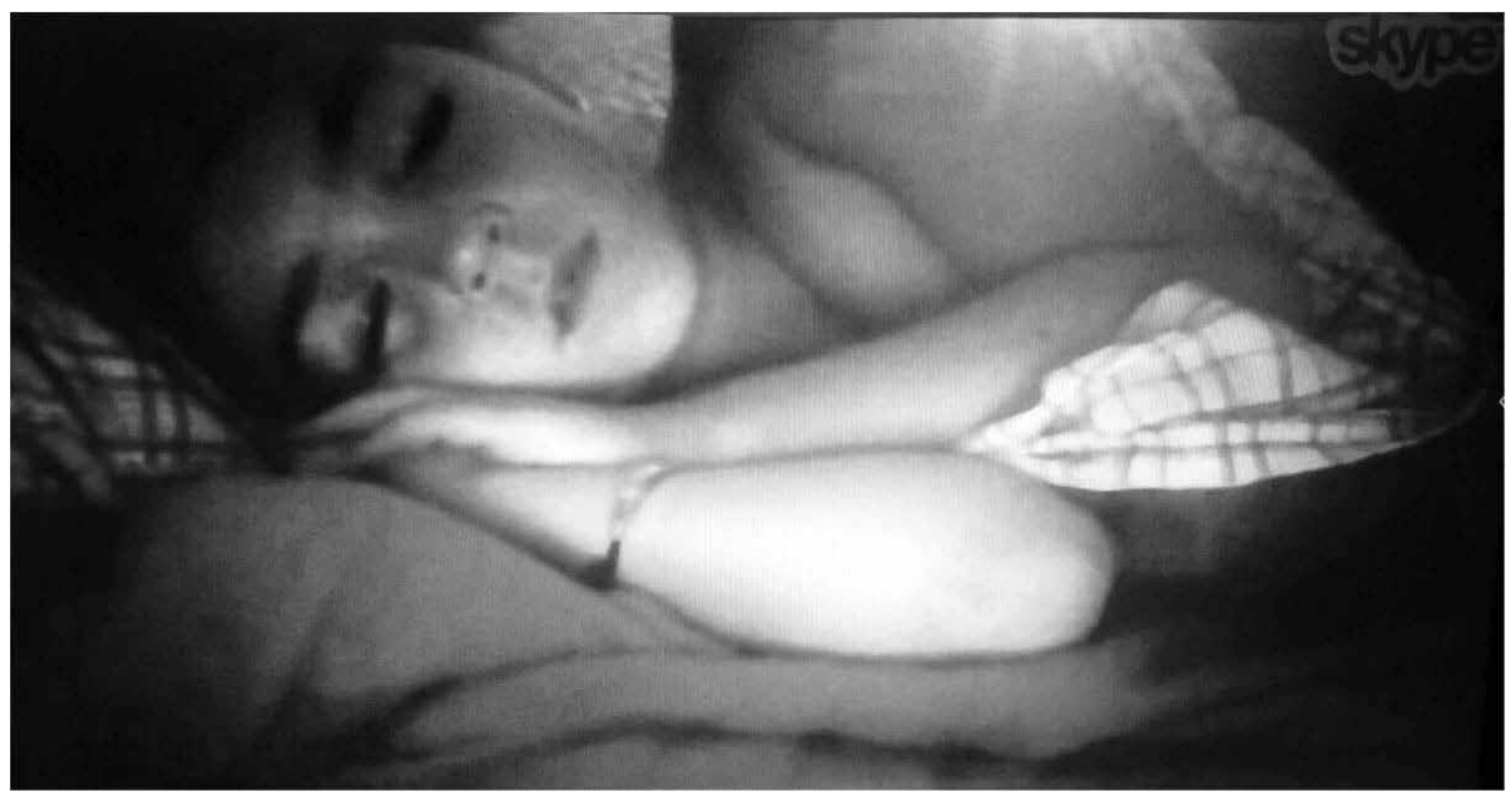

Mi primera reacción fue de emoción, aquella imagen que tenía en la pantalla del ordenador era más que conmovedora. A la vez, me sentía en la responsabilidad consciente de que necesitaba hacer algo con esa foto, compartir también mi propia incredulidad y sorpresa; en algún punto, transmitir la idea de poder ubicar en los requerimientos más cotidianos ciertas prácticas de cercanía que, aunque mediadas por formas tecnológicas, ponen a estas maneras en la perspectiva de un uso sensible en tanto tienen un carácter de acción humana.

Juan Martín Prada reflexiona respecto de este tema de manera esclarecedora y sintética

(el) grado de naturalización y cercanía propio de lo digital hace que las dinámicas y sistemas de actuación característicos de la nueva cultura informática y tecnológica, sus órdenes de sentido y valor, se nos hagan muy familiares $y$, por ello seamos cada vez menos conscientes de su activa presencia y de sus inmenso poder en la estructuración de valores sociales (no olvidemos que ninguna máquina 'informacional' es simplemente técnica, que todas estas máquinas son siempre 'máquinas sociales'). (2012, p. 137)

Ben Agger dice que "es posible ver estas tecnologías de forma juguetona. Pueden ser orientadas a las necesidades humanas, definidas y diseñadas para facilitar la necesidad de comunicarse, ser escuchados, adquirir y desarrollar conocimientos, escribir y tocar el alma." (2013, p. 26) Y yo creo que tiene razón, porque en la medida en "que más teoricemos lo digital - pensemos clara y estructuralmente acerca de esto - menos seremos utilizados por ello." (2013, p. 27)

En un sentido, las formas que habíamos logrado en la comunicación Maite y yo, no sólo me interpelaban en el ejercicio de mi paternidad, sino en mi condición de profesor universi- 
tario preocupado por las cuestiones de las visualidades y las artes. Sentía que alguien que intenta centrar sus aportaciones académicas en el espacio de los estudios de Cultura Visual, debía hacer algo con estas experiencias, y este texto me da la oportunidad de hacerlo con orden y reflexión, sin sensiblería.

\section{Concluir para formar redes de relatos}

Cada vez con mayor incidencia social, afectiva y de producción de deseo los medios digitales y las nuevas tecnologías forman parte de nuestras acciones cotidianas, con el grado de naturalización que esto conlleva, tal y como discutimos en este texto. Conviene aquí recurrir nuevamente a Prada para reflexionar sobre el asunto:

Al igual que cocinar, por ejemplo, es un medio con el que la naturaleza se convierte en cultura, parece que el empleo de los ordenadores y dispositivos digitales en nuestros días, con esa adaptabilidad ergonómica, portabilidad y cercanía que los caracteriza, está convirtiendo lo informático en una especie de segunda 'naturaleza'. Sus aplicaciones comunicativas de registro y de procesamiento, se presentan como medios protésicos del cuerpo y de la conciencias, generadores, incluso, de lo que podríamos denominar como una nueva tipología de 'lenguaje natural'. (2012, p. 137)

Las pequeñas anécdotas personales aquí reunidas constituian para mí un material interesante que debía ser liberado a su conocimiento, pero también analizado en sus implicancias conceptuales, para desnaturalizar las tecnologías digitales y sus usos, volverlas a una posibilidad humana, a partir de esas narraciones autobiográficas significativas.

Recuperar anécdotas, relatos, imágenes y cualquier otro material vital que merezca ser incluido en una biografía personal reviste una gran importancia para el narrador.
Permite tomar distancia y aproximarse alternativamente a un conjunto de situaciones que terminan construyendo una unidad provisoria de análisis y reflexión en la que aparecen nuevos conocimientos basados en interpretaciones, explicaciones, y síntesis de unos materiales originalmente diversos aunque constituyan parte de una misma trayectoria de vida.

Denzin parece tener razón en esto:

Algo nuevo está siempre apareciendo y desplazando lo que previamente era cierto y visto. No hay verdad en la pintura de la vida, sólo múltiples imágenes y rastros de lo que ha sido, lo que podría haber sido, y lo que es ahora. No hay una distinción firme entre los textos y las actuaciones. El tema de la autoetnografía interpretativa son las experiencias de vida y las actuaciones de una persona. $(2014$, p. 1)

Ser profesor, como ser padre o cualquier otra asignación nominal de un lugar social, necesariamente construido en lo colectivo, conlleva mandatos esperados, comportamientos aceptables, roles aprendidos. Lo interesante de hurgar en las biografias de las personas, como en la propia, es desentrañar los acontecimientos vitales que construyen nuestras identidades y sus representaciones e interpretaciones.

Tales hechos, siempre fragmentarios, son traídos a la interpretación en el presente en formas de recuerdo, donde las visualidades revelan su lugar fundamental en las biografias. Tanto cuando nuestra memoria recupera episodios exhumados en imágenes, como cuando acudimos a los objetos que guardamos materialmente, accedemos a unos restos visuales que conforman el material de la escritura de nuestras experiencias.

El interés agregado es que todos esos trazos biográficos no se producen en solitario, necesariamente involucran a otras personas, y dan cuenta, por eso, de acontecimientos colectivos, de subjetividades que se entremez- 
clan finalmente en otras biografias próximas y lejanas. En ellas es posible reconocernos y diferenciarnos también, encontrar elementos de común interpretación, conocer alternativas, asumir diversidades, en definitiva construir conocimiento.

\section{Referencias}

AGGER, Ben. Texting Toward Utopia: Kids, Writing, and Resistance. Boulder: Paradigm Publishers, 2013.

ANDREWS, Molly. Learning from stories, stories of learning. In: GOODSON, Ivor; LOVELESS, Avril; STEPHENS, David. Explorations in narrative reasearch. Rotterdam: Sense Publishers, 2012. p. 33-41.

BAUMAN, Zygmunt. Amor líquido: acerca de la fragilidad de los vínculos humanos. Trad. Mirta Rosenberg y Jaime Arrambid. Buenos Aires: FCE, 2005.

BENJAMIN, Walter. Historias y relatos. Trad. de Gonzalo Ortega. Barcelona: El Aleph, 2005.

BOURDIEU, Pierre. La ilusión biográfica. Historia y fuente oral. Barcelona, n. 2, p. 27-33, 1989.

CAMNITZER, Luis. Dialéctica de la liberación. Arte conceptualista latinoamericano. Montevideo: Casa Editorial HUM: 2008.

DENZIN, Norman. Interpretive auto ethnography. 2. ed. Los Angeles, CA: Sage, 2014.

HERRMANN, Andrew. My father's ghost: interrogating family photos. Journal of Loss and Trauma, $v$.
Es por eso, también, que decidí compartir este texto con gente que, estoy convencido, tendrá la sensibilidad suficiente para saber de qué va el tema. Porque siempre hay padres y niñas aunque se lleve la responsabilidad de profesor universitario.

10, p. 337-346, 2005.

HUERTA, Ricard. Paternidades creativas. Barcelona: GRAO, 2013.

MIRZOEFF, Nicholas. How to see the world: an introduction to images, from self-portraits to selfies, maps to movies, and more. New York: Basic Books, 2016.

PASSEGGI, Maria da Conceição; SOUZA, Elizeu Clementino; VICENTINI Paula Perin. Entre a vida e a formação: pesquisa (auto)biográfica, docência e profissionalização. Educação em Revista, Belo Horizonte, v. 27, n. 1, p. 369-386, abr. 2011.

PRADA, Juan Martín. Prácticas artísticas e internet en la época de las redes sociales. Madrid: Akal, 2012.

SOUZA, Elizeu Clementino. (Auto)biografia, histórias de vida e práticas de formação. In: NASCIMENTO, Antônio Dias; HETKOWSKI, Tânia Maria. (Orgs.). Memória e formação de professores [on-line]. Salvador: EDUFBA, 2007. p. 59-74.

Recebido em: 05.01.2017

Aprovado em: 25.03.2017

Fernando Miranda Doctor en Bellas Artes - Educación Artística (Facultad de Bellas Artes - Universidad de Barcelona - España). Licenciado en Ciencias de la Educación (Universidad de la República - Uruguay). Profesor Titular e Investigador del Instituto "Escuela Nacional de Bellas Artes" de la Universidad de la República - Uruguay; coordina desde su creación en 2005 el Núcleo de investigación en "Cultura Visual, educación y construcción de identidad". Ha integrado en carácter de miembro titular las Comisiones Sectoriales de Enseñanza (CSE) (2004-2008) e Investigación Científica (CSIC) (2008-2012) de la Universidad de la República. Es miembro investigador del grupo de pesquisa en "Cultura Visual e Educação" de la Facultad de Artes Visuales - Universidade Federal de Goiás. e-mail: fmiranda68@gmail.com

Instituto “Escuela Nacional de Bellas Artes - Universidad de la Republica (UDELAR), Montevideo, Uruguay. José Martí 3328, CP 11300. Fone: 27087600. 